| Volume-1 | Issue-1| Jun-Jul -2019 |

Short Communication

\title{
Psychiatric Pharmacy: New Role of Pharmacists in Mental Health
}

\author{
Abdul Kader Mohiuddin* \\ Bangladesh

\section{*Corresponding Author} \\ Abdul Kader Mohiuddin

\section{Article History} \\ Received: 02.07.2019 \\ Accepted: 16.07 .2019 \\ Published: 30.07 .2019
}

Assistant Professor, Department of Pharmacy, World University of Bangladesh, 151/8, Green Road, Dhanmondi, Dhaka - 1205,

\begin{abstract}
Psychiatric disorders are one of the major causes of global burden of diseases. Stigma remains a major impediment in the delivery of mental healthcare. It has been found across various studies that attitudes of doctors of other specialties and other healthcare professionals also contribute to stigma due to their lack of knowledge and awareness about psychiatry and mental health problems. The number of mental health professionals remains abysmally low. Community pharmacists are accessible, knowledgeable, and capable of providing mental health promotion and care in communities. This may not be a role that is recognized by the public, and men in particular. However, psychotherapy paired with medication is the most effective way to promote recovery. Examples include: Cognitive Behavioral Therapy, Exposure Therapy, Dialectical Behavior Therapy, etc. Pharmacists can play a key role by providing mental health medication management support to improve access and address patients' mental health needs.
\end{abstract}

Keywords: mental health; mental disorders; social stigma; barriers to access mental health; anxiety and depression

\section{Short Communication}

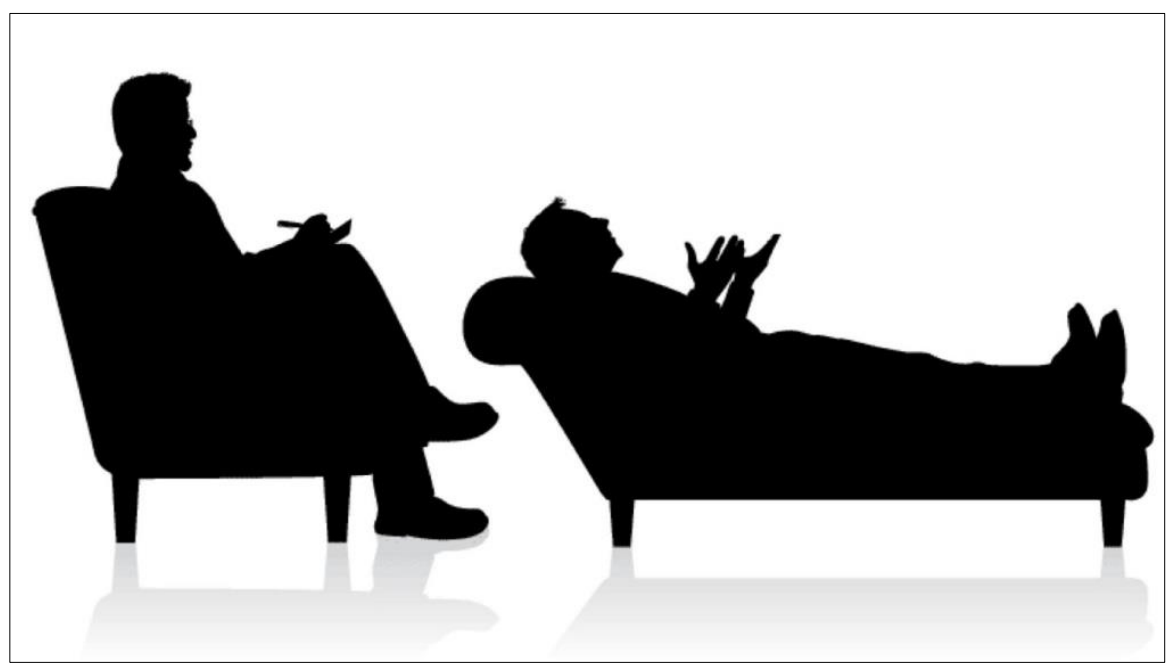

Fig-1: Changing the Conversation About Mental Health (MH) [1].

Talking about MH is the first step in overcoming the stigma that encompasses it. As we start to better understand the experiences of those whose lives are affected by $\mathrm{MH}$ issues, we also start to build connections that help people live healthier, freer and less painful existences.

Almost 1 in 5 adults (44 million) in the US experiences mental illness and distress in a given year, according to the NAMI. A nearly 10 million experience a debilitating mental illness that substantially interferes with their QoL [1,2]. Mental and addictive disorders affected more than 1 billion people globally in 2016. They caused $7 \%$ of all global burden of disease as measured in DALYs

Copyright @ 2019: This is an open-access article distributed under the terms of the Creative Commons Attribution license which permits unrestricted use, distribution, and reproduction in any medium for non commercial use (NonCommercial, or CC-BY-NC) provided the original author and source are credited. 
and $19 \%$ of all years lived with disability [3]. Depression was the leading cause of disability in the world, and suicide was the 10 th leading cause of death in 2015 [2]. Major depressive disorder (MDD) is the fourth cause of disability around the world and is estimated to be the second leading cause of disability by 2020 [4]. Over the past 20 years the prevalence of child and adolescent mental disorders in high-income countries has not changed despite increased investment in $\mathrm{MH}$ services. Insufficient contact with $\mathrm{MH}$ services may be a contributing factor [5]. In EU, factors that had the strongest association with depression were chronic diseases, pain, limitations in daily living, grip strength and cognitive impairment. The gap in $\mathrm{MH}$ service use was nearly $80 \%$ [6]. The treatment gap in developing countries was $76 \%-85 \%$, according to WHO. According NMHS, it is $83 \%$ in India for mental disorder and $86 \%$ for alcohol use disorders [7]. Swaminath et.al, 2019 stated that mental morbidity above the age of 18 years is $10.6 \%$ with a lifetime prevalence of $13.7 \%$. This means that 150 million Indians need active intervention [8]. Canadian Mental Health Association estimated that 500,000 Canadians miss work every week due to $\mathrm{MH}$ issues, costing the Canadian economy approximately $\$ 51$ billion dollars per year, as reported by Hayes et.al, 2019 [9]. According to Australian Bureau of Statistics (ABS) National Survey of Mental Health and Wellbeing (NSMHWB) $45 \%$ of Australians had experienced a mental disorder in their lifetime, with $20 \%$ experiencing a mental disorder in the previous year [10]. Refugees and asylum seekers often have increased MH needs, yet may face barriers in accessing MHPSS services in destination countries [11]. Also, Pauly et.al, 2018 stated that mental illness can be a function or cause of homelessness, and $60 \%$ of chronically homeless individuals have a serious mental illness (including major mood or psychotic disorders) [12]. Shpigelman et.al, 2019 reported that individuals with invisible psychiatric disabilities have lower levels of self-concept and body image compared to individuals with visible physical disabilities. Gender, family status and the severity level of the disability were found to be associated with self-concept and body image [13]. Plana-Ripoll et.al, 2019 reported that, among respondents with at least 1 mental disorder, more or less $50 \%$ have 1 or more additional lifetime diagnoses [14]. Mental disorders and suicide resulting from overwork or work-related stress have become major occupational health issues worldwide, particularly in Asian countries [15]. Depression and anxiety in more common chronic physical conditions such as CHD or diabetes can be associated with increased mortality, as reported Uhlenbusch et.al, 2019. Additionally, depression is associated with an increase of about $50 \%$ in costs of chronic medical illness [16]. Rokach et.al, 2019 reported that anxiety and depression lead to sexual dysfunction is between $30 \%$ and $70 \%$ in sexually active men and women in high-income countries [17]. Despite psychiatry's current status as the sixth largest medical specialty, the supply of available clinicians has not kept up with demand [18]. Outside of the diagnosis and treatment of depression, PCPs indicate a lack of comfort in treating PCMH patients with MH disorders [19]. Efforts to improve the outcomes of patients with mental illness often have involved incorporating the skills of a variety of health care professionals into collaborative care models. For over 40 years, clinical pharmacists have contributed to these care models in capacities ranging from educator to consultant to provider [20]. Medicines are a major treatment modality of management for many mental illnesses and pharmacists are therefore well positioned to enhance $\mathrm{MH}$ services with the potential to reduce the associated burden of mental disorders [21]. A study conducted by the CDC estimated that $22 \%$ of American adults had filled a prescription for anxiolytics, hypnotics, anticonvulsants, and antidepressants in the past 30 days [22]. According to epidemiological studies, about $70 \%$ of patients with depression and anxiety are treated in PHC, and about 75\% of all antidepressants are prescribed by general practitioners (GPs), reported by Skoglund et.al, 2019. In 2014 depression was the main diagnosis in about $35 \%$ of all cases of prolonged sick leave ( $\geq 60$ days) [23]. Antidepressant drug treatment (ADT), alone or in combination with psychotherapy, is recommended by the CANMAT for a minimum duration of 8 months. However, a large proportion of individuals show suboptimal adherence to ADT. In previous studies, more than $35 \%$ to $70 \%$ ceased treatment within 6 months, with up to $25 \%$ to $40 \%$ of patients having ceased their treatment within the first month [24,25]. Also, Holvast et.al, 2019 reported non-adherence to antidepressants is high among older patients with depression in primary care settings [26]. Even after achieving remission, depression has higher rates of recurrence in up to $80 \%$ of all MDD patients with odds of becoming chronic in $20 \%$ of patients. The onset of each new major depressive episode increases the chances of relapse, chronicity, and treatment-resistant depression [27]. 10\%-30\% of MDD patients do not improve or show a partial response coupled with functional impairment, poor quality of life, suicide ideation and attempts, self-injurious behavior, and a high relapse rate [28]. Pharmacists are highly accessible health care professionals, trusted by the public and have regular interactions with consumers that suffer acute mental illness [29,30]. Medication counselling provided by community pharmacists is an important source of medication information for patients and their caregivers. Community-pharmacy based medication counselling interventions have resulted in improved patient adherence to antidepressant and antipsychotic medications [31]. Transitions in care have the potential to be destabilizing periods for many patients and is an area where pharmacist-performed medication therapy management (MTM) has been found to be beneficial [32]. The pharmacist interim prescriber clinic was associated with a significant decrease in mean number of patients seen per month in PES [18]. The clinical pharmacist can make an impact by improving mild-to-moderate $\mathrm{MH}$ conditions, promoting interdisciplinary collaboration, and increasing documentation and follow-up that align with published treatment guidelines [2]. Chavez et.al, 2019 reported that pharmacists improved rate of patient interest in behavioral health counseling during the consult and recommending counseling directly to the patient or even initiating the referral themselves [33]. Bingham et.al, 2018 highlighted the value of the pharmacist's involvement, suggesting the potential for improved nutrition, physical activity, and sleep for patients with $\mathrm{MH}$ conditions, at least in the short term [34]. Throughout the United States, pharmacists have crafted interventions designed to prevent, identify, and manage opioid misuse and abuse [35]. Also, Eltorki et.al, 2019 reported that physicians and nurses have mostly positive perceptions and expectations from clinical pharmacists at the psychiatric hospital [36]. In Australia, The Pharmaceutical Society's Mental Healthcare Framework recognizes pharmacists as primary health care professionals who have an important role to play within $\mathrm{MH}$ care. Globally, the International Pharmaceutical Federation has urged members to include pharmacists as part of their "human resource development policy" so that "an increase by $20 \%$ of service coverage for severe mental disorders can be achieved." [37]. Murphy et.al, 2016 says pharmacists are not practicing to their full scope of practice in mental illness and addictions care for several 
reasons including limitations within the work environment and lack of structures and processes in place to be fully engaged as health care professionals [38]. Sexual dysfunction is an underdiscussed adverse effect to antidepressants and may increase the risk for discontinuation and nonadherence to antidepressant pharmacotherapy [39-42]. Sildenafil effectively improved erectile function and other aspects of sexual function in men with sexual dysfunction associated with the use of SSRI antidepressants [43]. Clinical pharmacists increased their skillset for treating depression and anxiety and enhanced their ability to make interventions with patients who are referred to them for other chronic disease state management (e.g. hypertension, chronic pain) [44]. Though pharmacists are trained in psychopharmacology, they lack formal MH intervention skills [29]. A solution to address this gap is to up-skill pharmacists in mental health first aid MHFA. It is an educational program geared towards educating MHFA responders to assist those who may be experiencing a $\mathrm{MH}$ condition or disorder [45]. Latzman et.al, 2019 reported that approximately $20 \%$ to $50 \%$ of adults with SMI did not receive past-year MH services [46]. Douglass et.al, 2019 reported that stigma has a significant impact on the treatment of $\mathrm{MH}$, with substantial implications on patient quality of life. To provide professional, culturally sensitive care, pharmacists should reflect on their skills, attitudes, and beliefs of $\mathrm{MH}$ treatment and actively participate in changing the stigma of mental illnesses [47]. Evidence suggests that socioeconomic factors can have the greatest effect on health and wellbeing, accounting for $40 \%$ of all influences on the individual. Taylor et.al, 2019 recommended inclusion of pharmacy team in social prescribing pathways would widen the ability to support people with psychosocial needs arising from non-medical determinants and reach people who are unable to access general practice health services [48]. The complexity of psychotropic drug therapy would be expected to increase, and the challenges inherent to the safe pharmacological treatment of mental disorders will expand. The merits of a partnership approach with collaborative work involving psychiatrists and pharmacists have been established [49]. With provider education and appropriate physician champions, pharmacists are able to work collaboratively with psychiatrists in an MH clinic [50]. A PCMHI clinical pharmacy specialist (CPS) successfully manages and maintains patients with uncomplicated $\mathrm{MH}$ conditions in primary care through evidence-based pharmacotherapy, as evidenced by symptom improvement, medication adherence, and low rate of specialty $\mathrm{MH}$ referrals [51].

\title{
Acknowledgement
}

I'm thankful to Dr. Om Prakash Singh, Professor of Psychiatry, WBMES and Consultant Psychiatrists, AMRI Hospital, Dhakuria, Kolkata, West Bengal, India for his valuable time to audit my paper and for his thoughtful suggestions. I'm also grateful to seminar library of Faculty of Pharmacy, University of Dhaka and BANSDOC Library, Bangladesh for providing me books, journal and newsletters.

\begin{abstract}
Abbreviations
National Alliance on Mental IIIness (NAMI); Quality of Life (QoL); Primary Care Providers' (PCPs'); Patient-Centered Medical Homes (PCMHs); mental health and psychosocial support (MHPSS); Australian Bureau of Statistics (ABS); National Survey of Mental Health and Wellbeing (NSMHWB); coronary heart disease (CHD); National Mental Health Survey (NMHS); Mental Health (MH); medication therapy management (MTM); psychiatric emergency services (PES); Antidepressant drug treatment (ADT); Canadian Network for Mood and Anxiety Treatments (CANMAT); Centers for Disease Control and Prevention (CDC); Major depressive disorder (MDD); Mental Health First Aid TM (MHFA); Primary Care Mental Health Integration (PCMHI); clinical pharmacy specialist (CPS); Selective Serotonin Reuptake Inhibitor (SSRI)
\end{abstract}

\section{Financial Disclosure or Funding: N/A}

Conflict of Interest: The author declares that he has no competing interests.

\section{Informed Consent: N/A}

\section{Author contributions: N/A}

\section{References}

1. Minds, A. Changing the Conversation About Mental Health; 2009.. 18.

2. Harms, M., Haas, M., Larew, J., \& DeJongh, B. (2017). Impact of a mental health clinical pharmacist on a primary care mental health integration team. Mental Health Clinician, 7(3), 101-105.

3. Rehm, J., \& Shield, K. D. (2019). Global Burden of Disease and the Impact of Mental and Addictive Disorders. Current psychiatry reports, 21(2), 10.

4. Faquih, A. E., Memon, R. I., Hafeez, H., Zeshan, M., \& Naveed, S. (2019). A Review of Novel Antidepressants: A Guide for Clinicians. Cureus, 11(3).

5. Mulraney, M., Hiscock, H., Sciberras, E., Coghill, D., \& Sawyer, M. (2019). Mental health difficulties across childhood and mental health service use: findings from a longitudinal population-based study. The British Journal of Psychiatry, 1-6.

6. Horackova, K., Kopecek, M., Machů, V., Kagstrom, A., Aarsland, D., Motlova, L. B., \& Cermakova, P. (2019). Prevalence of latelife depression and gap in mental health service use across European regions. European Psychiatry, 57, 19-25.

7. Singh, O. P. (2018). Closing treatment gap of mental disorders in India: Opportunity in new competency-based Medical Council of India curriculum. Indian journal of psychiatry, 60(4), 375. 
8. Swaminath, G., Enara, A., Rao, R., Kumar, K. V. K., \& Kumar, C. N. (2019). Mental Healthcare Act, 2017 and homeless persons with mental illness in India. Indian Journal of Psychiatry, 61(Suppl 4), S768.

9. Hayes, K., Berry, P., Ebi, KL. (2019) Factors Influencing the Mental Health Consequences of Climate Change in Canada. Int J Environ Res Public Health. 6(4);16.

10. Cook, L. (2019).Mental health in Australia: a quick guide. Parliament of Australia, 14 February.

11. Satinsky, E., Fuhr, D. C., Woodward, A., Sondorp, E., \& Roberts, B. (2019). Mental health care utilisation and access among refugees and asylum seekers in Europe: A systematic review. Health Policy.

12. Pauly, J. B., Moore, T. A., \& Shishko, I. (2018). Integrating a mental health clinical pharmacy specialist into the Homeless Patient Aligned Care Teams. Mental Health Clinician, 8(4), 169-174.

13. Shpigelman, C. N., \& HaGani, N. (2019). The impact of disability type and visibility on self-concept and body image: Implications for mental health nursing. Journal of psychiatric and mental health nursing, 26(3-4), 77-86.

14. Plana-Ripoll, O., Pedersen, C. B., Holtz, Y., Benros, M. E., Dalsgaard, S., De Jonge, P., ... \& Gunn, J. (2019). Exploring comorbidity within mental disorders among a Danish national population. JAMA psychiatry, 76(3), 259-270.

15. Yamauchi, T., Sasaki, T., Yoshikawa, T., Matsumoto, S., \& Takahashi, M. (2018). Incidence of overwork-related mental disorders and suicide in Japan. Occupational medicine, 68(6), 370-377.

16. Uhlenbusch, N., Löwe, B., Härter, M., Schramm, C., Weiler-Normann, C., \& Depping, M. K. (2019). Depression and anxiety in patients with different rare chronic diseases: A cross-sectional study. PloS one, 14(2), e0211343.

17. Rokach, A. The Effect of Psychological Conditions on Sexuality: A Review. Psychol Psychother Res Stud. 2(2).

18. Gibu, M., Clark, J., \& Gold, J. (2017). Mental health pharmacists as interim prescribers. Mental Health Clinician, 7(3), 111-115.

19. Coe, A. B., Bostwick, J. R., Choe, H. M., \& Thompson, A. N. (2019). Provider perceptions of pharmacists providing mental health medication support in patient-centered medical homes. Journal of the American Pharmacists Association.

20. Finley, P. R., Crismon, M. L., \& Rush, A. J. (2003). Evaluating the impact of pharmacists in mental health: a systematic review. Pharmacotherapy: The Journal of Human Pharmacology and Drug Therapy, 23(12), 1634-1644.

21. Rubio-Valera, M., Chen, T., \& O'Reilly, C. (2014). New roles for pharmacists in community mental health care: a narrative review. International journal of environmental research and public health, 11(10), 10967-10990.

22. Goodman, C. S., Smith, T. J., \& LaMotte, J. M. (2017). A survey of pharmacists' perceptions of the adequacy of their training for addressing mental health-related medication issues. Mental Health Clinician, 7(2), 69-73.

23. Skoglund, I., Björkelund, C., Svenningsson, I., Petersson, E. L., Augustsson, P., Nejati, S., ... \& Hange, D. (2019). Influence of antidepressant therapy on sick leave in primary care: ADAS, a comparative observational study. Heliyon, 5(1), e01101.

24. Guillaumie, L., Ndayizigiye, A., Beaucage, C., Moisan, J., Grégoire, J.P., Villeneuve, D., Lauzier, S. (2018) Patient perspectives on the role of community pharmacists for antidepressant treatment: A qualitative study. Can Pharm J (Ott). 151(2),142-148.

25. Srimongkon, P., Aslani, P., \& Chen, T. F. (2018). Consumer-related factors influencing antidepressant adherence in unipolar depression: a qualitative study. Patient preference and adherence, 12, 1863.

26. Holvast, F., Oude Voshaar, R. C., Wouters, H., Hek, K., Schellevis, F., Burger, H., \& Verhaak, P. F. (2018). Non-adherence to antidepressants among older patients with depression: a longitudinal cohort study in primary care. Family practice, 36(1), 12-20.

27. Florea, I., Danchenko, N., Brignone, M., Loft, H., Rive, B., \& Abetz-Webb, L. (2015). The effect of vortioxetine on health-related quality of life in patients with major depressive disorder. Clinical therapeutics, 37(10), 2309-2323.

28. Al-Harbi, K. S. (2012). Treatment-resistant depression: therapeutic trends, challenges, and future directions. Patient preference and adherence, 6, 369.

29. Kirschbaum, M., Peterson, G., \& Bridgman, H. (2016). Mental health first aid training needs of Australian community pharmacists. Currents in Pharmacy Teaching and Learning, 8(3), 279-288.

30. Murphy, A. L., \& Gardner, D. M. (2019). Pharmacists' acceptability of a men's mental health promotion program using the Theoretical Framework of Acceptability. AIMS public health, 6(2), 195.

31. Aaltonen, S. E., Laine, N. P., Volmer, D., Gharat, M. S., Muceniece, R., Vitola, A., ... \& Bell, J. S. (2010). Barriers to medication counselling for people with mental health disorders: a six country study. Pharmacy practice, 8(2), 122.

32. American Pharmacists Association. (2008). National Association of Chain Drug Stores Foundation. Medication therapy management in pharmacy practice: core elements of an MTM service model (version 2.0) J Am Pharm Assoc, 48, 341-353.

33. Chavez, B., \& Kosirog, E. (2019). Impact on an integrated psychiatric pharmacy service in a primary care clinic. Mental Health Clinician, 9(4), 269-274.

34. Bingham, J., Axon, D., Scovis, N., \& Taylor, A. (2019). Evaluating the Effectiveness of Clinical Pharmacy Consultations on Nutrition, Physical Activity, and Sleep in Improving Patient-Reported Psychiatric Outcomes for Individuals with Mental Illnesses. Pharmacy, 7(1), 2.

35. Riley, T. B., \& Alemagno, S. (2019). Pharmacist utilization of prescription opioid misuse interventions: Acceptability among pharmacists and patients. Research in Social and Administrative Pharmacy.

36. Eltorki, Y., Abdallah, O., Omar, N., \& Zolezzi, M. (2019). Perceptions and expectations of health care providers towards clinical pharmacy services in a mental health hospital in Qatar. Asian journal of psychiatry, 42, 62-66.

37. El-Den, S., Chen, T. F., Moles, R. J., \& O'Reilly, C. (2018). Assessing mental health first aid skills using simulated patients. American journal of pharmaceutical education, 82(2), 6222. 
38. Murphy, A. L., Phelan, H., Haslam, S., Martin-Misener, R., Kutcher, S. P., \& Gardner, D. M. (2016). Community pharmacists' experiences in mental illness and addictions care: a qualitative study. Substance abuse treatment, prevention, and policy, 11(1), 6.

39. Jing, E., \& Straw-Wilson, K. (2016). Sexual dysfunction in selective serotonin reuptake inhibitors (SSRIs) and potential solutions: A narrative literature review. Mental Health Clinician, 6(4), 191-196.

40. Higgins, A., Nash, M., \& Lynch, A. M. (2010). Antidepressant-associated sexual dysfunction: impact, effects, and treatment. Drug, healthcare and patient safety, 2, 141.

41. Clayton, A. H., Croft, H. A., \& Handiwala, L. (2014). Antidepressants and sexual dysfunction: mechanisms and clinical implications. Postgraduate medicine, 126(2), 91-99.

42. Baldwin, D. S., \& Foong, T. (2013). Antidepressant drugs and sexual dysfunction. The British Journal of Psychiatry, 202(6), 396397.

43. Nurnberg, H. G., Hensley, P. L., Gelenberg, A. J., Fava, M., Lauriello, J., \& Paine, S. (2003). Treatment of antidepressantassociated sexual dysfunction with sildenafil: a randomized controlled trial. Jama, 289(1), 56-64.

44. Locke, A., \& Kamo, N. (2016). Utilizing clinical pharmacists to improve delivery of evidence-based care for depression and anxiety in primary care. BMJ Open Quality, 5(1), u211816-w4748.

45. Chowdhary, A., Zlotnikova, V., Lucas, C., \& Lonie, J. M. (2019). How do mental health first aid ${ }^{\mathrm{TM}}$ interventions influence patient help-seeking behaviours? A dilemma for pharmacist mental health first aid responders. Research in Social and Administrative Pharmacy, 15(1), 106-108.

46. Latzman, N. E., Ringeisen, H., Forman-Hoffman, V. L., Munoz, B., Miller, S., \& Hedden, S. L. (2019). Trends in mental health service use by age among adults with serious mental illness. Annals of epidemiology, 30, 71-73.

47. Douglass, M., \& Moy, B. (2019). Evaluation of the impact of a social media-focused intervention on reducing mental health stigma among pharmacy students. Mental Health Clinician, 9(3), 110-115.

48. Taylor, D. A., Nicholls, G. M., \& Taylor, A. D. (2019). Perceptions of Pharmacy Involvement in Social Prescribing Pathways in England, Scotland and Wales. Pharmacy, 7(1), 24.

49. Alderman, C. P., \& Lucca, J. M. (2017). Psychiatry and clinical pharmacy: A logical partnership. Indian journal of psychiatry, 59(2), 138.

50. Tallian, K. B., Hirsch, J. D., Kuo, G. M., Chang, C. A., Gilmer, T., Messinger, M., ... \& Lee, K. C. (2012). Development of a pharmacist-psychiatrist collaborative medication therapy management clinic. Journal of the American Pharmacists Association, 52(6), e252-e258.

51. Herbert, C., \& Winkler, H. (2018). Impact of a clinical pharmacist-managed clinic in primary care mental health integration at a Veterans Affairs health system. Mental Health Clinician, 8(3), 105-109. 